Original article

\title{
Determination of the staphylococcal cassette chromosome in methicillin-resistant Staphylococcus aureus strains isolated from various clinical samples
}

\author{
Aysegül Copur-Cicek ${ }^{1}$, Rukiye Dinc-Patlak ${ }^{2}$, Cemal Sandalli ${ }^{1}$, Zafer Mengeloğlu ${ }^{3}$, Ugur Kostakoglu ${ }^{1}$, \\ Ilknur Esen Yildiz ${ }^{1}$ \\ ${ }^{1}$ Recep Tayyip Erdogan University, Rize, Turkey \\ ${ }^{2}$ Saxion University of Applied Sciences, Enschede, Netherlands \\ ${ }^{3}$ Abant Izzet Baysal University, Bolu, Turkey
}

Received 28 December 2015, Accepted 21 Januay 2016

(C) 2015, Copur-Cicek A., Dinc-Patlak R., Sandalli C., Mengeloğlu Z., Kostakoglu U., Yildiz I.E.

C 2015, Russian Open Medical Journal

\begin{abstract}
Aim - The present study aimed to detect mecA and staphylococcal cassette chromosome mec (SCCmec) types in methicillinresistant Staphylococcus aureus (MRSA) isolates obtained from various clinical samples in two university hospitals. It was also aimed to make comparison amongst the isolates.

Materials and Methods - A total of 99 MRSA strains isolated from various clinical samples between 2011-2015 were included in the study. Bacterial deoxyribonucleic acid (DNA) was extracted from Staphylococcus aureus strains using GF-1 DNA extraction Kit (Vivantis, Malaysia). mecA gene were detected, and SCCmec cassette types were determined by multiplex polymerase chain reaction (PCR) first, and following specific PCR. Specific MRSA strains such as COL type I, PER3 type la, and HU25 type Illa were used as the quality control strains for optimization of multiplex PCR. The amplification products were electrophoresed using agarose gel electrophoresis in TAE buffer (mixture of tris base, acetic acid and ethylenediaminetetraacetic acid).

Results - mecA gene was detected in 60 Staphylococcus aureus isolates, and these were identificated as MRSA. Amongst the MRSA strains, SCCmec type III was the most frequent cassette type (42 isolates, 70.0\%). SCCmec type I was detected in 27 isolates (45.0\%), type II was in 26 isolates (43.3\%), and type $\mathrm{V}$ in 23 isolates (38.3\%).

Conclusion - In the present study, the most frequent cassette was detected as SCCmec type III in concordance with the studies conducted in Turkey and in some regions in the world. In conclusion, determination of epidemiological and molecular characteristics of MRSA strains has critical importance because of the difficulties in the treatment and of the nosocomial infections and epidemics they caused. The data obtained would contribute to the preventions in terms of epidemiology.
\end{abstract}

Keywords: Staphylococcus aureus, methicillin-resistant Staphylococcus aureus, staphylococcal cassette chromosome mec

Cite as Copur-Cicek A, Dinc-Patlak R, Sandalli C, Mengeloğlu Z, Kostakoglu U, Yildiz IE. Determination of the staphylococcal cassette chromosome in methicillin-resistant Staphylococcus aureus strains isolated from various clinical samples. Russian Open Medical Journal 2016; 5: e0202.

Correspondence to Zafer Mengeloglu. E-mail: mengeloglu@gmail.com. Phone: +90-374-2534656. Fax: +90-374-253455.

\section{Introduction}

Methicillin-resistant Staphylococcus aureus (MRSA) was first reported in United Kingdom in 1961, just after the description of methicillin. Staphylococcus aureus is a Gram-positive coccus naturally found as a normal flora member of skin, nose, andmouth. Spread of MRSA has been a growing issue in whole world. Multiple resistance of MRSA isolates makes the treatment of the infection harder. In those infections, only a few antibiotics can be used [1-3].

MRSA strains have penicillin binding proteins (PBPs) such as PBP2a and PBP2'. PBP2a shows lower affinity to beta-lactam antibiotics in comparison to the other PBPs. PBPs are peptidases linked to the membrane, and play a role in combination of the peptidoglycan in the cell wall. PBP2a is encoded by mecA gene that is found in all methicillin-resistant staphylococci [3-5].
MRSA strains carry a mobile genetic element, staphylococcal cassette chromosome mec ( $\mathrm{SCCmec}$ ), in their genomes. SCCmec consists of ccr complex, mec complex and a J (Junkyard) region. Methicillin-resistance is provided via mecA carried by $\mathrm{SCCmec}$ cassette $[1,3,6]$.

$\mathrm{SCC}$ ec cassettes have differents types in the hospitalacquired (HA) or community-acquired (CA) strains. SCCmec types I, $\mathrm{II}$, and III are usually found in HA-MRSA isolates, and types IV and V are found in CA-MRSAs [4-6].

The present study aimed to detect mecA and SCCmec types in MRSA isolates obtained from various clinical samples in two university hospitals. It was also aimed to make comparison amongst the isolates. 
Table 1. Distribution of SCCmec types according to inpatients and outpatients

\begin{tabular}{|c|c|c|c|c|c|c|c|c|c|}
\hline & \multicolumn{8}{|c|}{ SCCmec types } & \multirow[t]{2}{*}{ Total } \\
\hline & Type I & Type II & Type III & Type IVa & Type IVb & Type IVc & Type IVd & Type V & \\
\hline Inpatients, n (\%) & $22(81.5)$ & $22(84.6)$ & $37(88.1)$ & $17(77.3)$ & $2(100.0)$ & $0(0.0)$ & $1(100.0)$ & $21(91.3)$ & $52(86.7)$ \\
\hline Outpatients, n (\%) & $5(18.5)$ & $4(15.4)$ & 5 (11.9) & $5(22.7)$ & $0(0.0)$ & $0(0.0)$ & $0(0.0)$ & $2(8.7)$ & $8(13.3)$ \\
\hline Total, $\mathrm{n}$ & 27 & 26 & 42 & 22 & 2 & 0 & 1 & 23 & 143 \\
\hline
\end{tabular}

Table 2. Antibiotic-resistance profiles of mecA-positive and mecA-negative Staphylococcus aureus isolates

\begin{tabular}{|c|c|c|c|c|c|c|c|c|}
\hline \multirow[t]{2}{*}{ Staphylococcus aureus isolates } & \multicolumn{8}{|c|}{ Number of antibiotic-resistant isolates } \\
\hline & PEN & OXA & ERY & DA & LNZ & $\mathrm{CN}$ & CIP & SXT \\
\hline mecA-positive, $\mathrm{n}(\%)$ & $60(100)$ & $59(98.3)$ & $23(38.3)$ & $16(26.7)$ & $6(10)$ & $22(36.7)$ & $31(51.7)$ & $7(11.7)$ \\
\hline mecA-negative, n (\%) & $8(100)$ & $8(100)$ & $1(12.5)$ & $1(12.5)$ & $0(0.0)$ & $1(12.5)$ & $3(37.5)$ & $1(12.5)$ \\
\hline
\end{tabular}

PEN, penicillin; OXA, oxacillin; ERY, erythromycin; DA, clindamycin; LNZ, linezolid; CN, gentamicin; CIP, ciprofloxacin; SXT, sulfamethoxazole/trimethoprim.

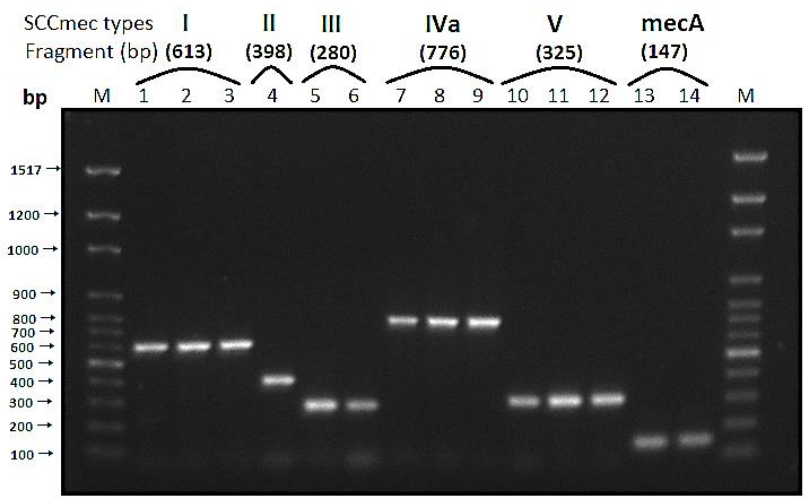

Figure 1. Amplification patterns of SCCmec types that occured using specific PCR parameters. Type I - lines 1, 2 and 3; type II - line 4; type III lines 5 and 6; type IVa - lines 7, 8 and 9; type V - lines 10, 11 and 12; mecA gene - lines 13 and 14; and line $\mathrm{M}$ - molecular weight marker, 100bp DNA Ladder.

\section{Material and Methods}

A total of 99 MRSA strains isolated from various clinical samples in the Recep Tayyip Erdogan University (Medical Microbiology Departments, Faculty of Medicine) (61 isolates), and the Abant Izzet Baysal University (Faculty of Medicine) (38 isolates) between 2011-2015 were included in the study. The isolates were frozen until the study at $-70^{\circ} \mathrm{C}$. Only one isolate per patient was included. The frozen strains were thawed, were inoculated onto blood agar media and were incubated overnight at $35^{\circ} \mathrm{C}$. The colonies growth were confirmed to be Staphylococcus aureus using the conventional tests such as Gram staining, catalase, and coagulase. Methicillin-resistance of the strains were confirmed using disk diffusion method with cefoxitin disk $(30 \mu \mathrm{g}$, Oxoid, England) according to the criteria of the Clinical and laboratory Standards Institute [7].

Bacterial deoxyribonucleic acid (DNA) was extracted from Staphylococcus aureus strains using GF-1 DNA extraction Kit (Vivantis, Malaysia). mecA gene were detected and ScCmec cassette types were determined by multiplex polymerase chain reaction (PCR) first, and following specific PCR using the primers reported by Zhang et al. [6]. Specific MRSA strains such as COL type I, PER3 type la, and HU25 type IIla were used as the quality control strains for optimization of multiplex PCR.
The amplification products were electrophoresed using agarose gel electrophoresis in TAE buffer (mixture of tris base, acetic acid and ethylenediaminetetraacetic acid).

Results

A total of 99 strains isolated from various clinical specimens were included in the study. Two of them could not be confirmed as S. aureus, and were excluded. A total of 82 of the rest 97 strains $(84.5 \%)$ were isolated from inpatients, 46 strains (47.4\%) were from women. The mean age was $56.3 \pm 13.45$ years. The distribution of methicillin-resistance according to inpatients or outpatients is shown in Table 1. Antibiotic resistance profiles are demonstrated in Table 2.

The MRSA strains isolated from tracheal aspirate (17 isolates), blood (15 isolates), wound (9 isolates), and other specimens (19 isolates) such as urine, nasal culture, abscess, and catheter were used. A total of $45 \%$ of the isolates were obtained from the intensive care units, $20 \%$ were from surgery clinics, $12 \%$ were from infectious diseases, and the rest $23 \%$ were from the other clinics.

mecA gene was detected in 60 Staphylococcus aureus isolates, and these were identificated as MRSA. Amongst the MRSA strains, $\mathrm{SCCmec}$ type III was the most frequent cassette type (42 isolates, $70.0 \%)$. SCCmec type I was detected in 27 isolates (45.0\%), type II was in 26 isolates (43.3\%), and type $\mathrm{V}$ in 23 isolates (38.3\%) (Table 1, Figure 1).

\section{Discussion}

Staphylococcus aureus is amongst the major nosocomial pathogens that causes severe infections including osteomyelitis, pneumonia, endocarditis, food poisoning, surgical wounds, and septicemia. Because the resistance problems, the treatment of this agent, particularly MRSA-caused infections, is becoming harder and more expensive $[6,8]$.

Determination of molecular typing of the strains can provide very useful information for management of the infection and a possible outbreak, and nosocomial transmission. There are few molecular methods available for bacteria. Amongst those, $\mathrm{ScCmec}$ typing, as used in the present study, is a useful tool for determination of the resistance mechanisms in MRSA strains [4, 6, 8].

Abd el Hamid et al. [9] detected SCCmec type IV in 48\% MRSA isolates in their study that was conducted in Egypt. Rahimi et al. 
[10] detected SCCmec type III in $28.6 \%$ of 653 Staphylococcus aureus isolates in Iran. Yu et al. [11] found SCCmec type IV as the most frequent cassette amongst 128 Staphylococcus aureus isolates. De Oliveira et al. [12] reported the most frequent cassette as SCCmec type II with a rate of $53.7 \%$ amongst 123 Staphylococcus aureus strains. Lee et al. [13] found the most frequent type as type I (8.7\%) amongst the community-acquired cases, and as type $\mathrm{V}(24.4 \%)$ amongst the hospital-acquired isolates.

In the studies conducted in Turkey, the variety of the most frequent SCCmec type hasn't been reported so large. Demirel et al. [14] found the most frequent SCCmec as type IIla in $64.7 \%$ of the nasal culture samples they collected from university students. Kirca-yilmaz et al. [15] reported the most frequent $\mathrm{SCCmec}$ as type III amongst 48 MRSA isolates. Yilmaz et al. [16] found SCCmec type III in $91 \%$ of the strains they isolated from 147 hospitalacquired MRSA cases. Gülmez et al. [17] also reported SCCmec type III in $87.6 \%$ MRSA strains. Baran et al. [18] detected SCCmec type III in $85.7 \%$ of MRSA isolates. Akoglu et al. [19] also found SCCmec type III as the most frequent cassette type in $61.8 \%$ of the MRSA strains they isolated from 110 hospital-acquired cases.

In the present study, the most frequent cassette was detected as SCCmec type III in concordance with the studies conducted in Turkey and in some regions in the world. Some recent studies report SCCmec type III as the most frequent type isolated from hospital-acquired infections. This can be explained as the studies conducted on the MRSA strains mostly isolated from nosocomial infections, as the present study $[12,13]$.

\section{Conclusion}

Determination of epidemiological and molecular characteristics of MRSA strains has critical importance because of the difficulties in the treatment and of the nosocomial infections and epidemics they caused. The data obtained would contribute to the preventions in terms of epidemiology.

\section{Conflict of interest: None to declare.}

\section{References}

1. Ito $T$, Hiramatsu $\mathrm{K}$, Oliveira DC, de Lencastre $\mathrm{H}$, Zhang $\mathrm{K}$, Westh $\mathrm{H}$, et al. Classification of staphylococcal cassette chromosome mec ( $\mathrm{SCCmec}$ ): guidelines for reporting novel SCCmec elements. Antimicrob Agents Chemother 2009; 53(12): 4961-4967. (doi: 10.1128/AAC.00579-09) (PMID: 19721075)

2. Pournajaf A, Ardebili A, Goudarzi L, Khodabandeh M, Narimani T, Abbaszadeh H. PCR-based identification of methicillin-resistant Staphylococcus aureus strains and their antibiotic resistance profiles. Asian Pac J Trop Biomed 2014; 4(Suppl 1): S293-S297. (doi: 10.12980/APJTB.4.2014C423) (PMID: 25183100)

3. Shore AC, Deasy EC, Slickers P, Brennan G, O'Connell B, Monecke S, et al. Detection of staphylococcal cassette chromosome mec type XI carrying highly divergent mecA, mecl, mecR1, blaZ, and ccr genes in human clinical isolates of clonal complex 130 methicillin-resistant Staphylococcus aureus. Antimicrob Agents Chemother 2011; 55(8): 3765-3773. (doi: 10.1128/AAC.00187-11) (PMID: 21636525)

4. Ostojić $M$, Hukić $M$. Genotypic and phenotypic characteristics of Methicillinresistant Staphylococcus aureus (MRSA) strains, isolated on three different geography locations. Bosn J Basic Med Sci 2015; 15(3): 48-56. (doi: 10.17305/bjbms.2015.402) (PMID: 26295294)

5. Milheiriço $C$, Oliveira DC, de Lencastre $H$. Update to the multiplex PCR strategy for assignment of mec element types in Staphylococcus aureus. Antimicrob Agents Chemother 2007; 51(9): 3374-3377. (doi: 10.1128/AAC.00275-07) (PMID: 17576837)

6. Zhang K, McClure JA, Elsayed S, Louie T, Conly JM. Novel multiplex PCR assay for simultaneous identification of community-associated methicillin-resistant Staphylococcus aureus strains USA300 and USA400 and detection of mecA and Panton-Valentine leukocidin genes, with discrimination of Staphylococcus aureus from coagulasenegative staphylococci. J Clin Microbiol 2008; 46(3): 1118-1122. (doi: 10.1128/JCM.01309-07) (PMID: 18160447)

7. Clinical and Laboratory Standards Institute. Performance standards for antimicrobial susceptibility testing. 18th Information Supplement. 2008. CLSI Document M100-18. CLSI, Wayne, PA.

8. Asghar $\mathrm{AH}$. Molecular characterization of methicillin-resistant Staphylococcus aureus isolated from tertiary care hospitals. Pak J Med Sci 2014; 30(4): 698-702. (PMID: 25097499)

9. Abd El-Hamid MI, Bendary MM. Comparative phenotypic and genotypic discrimination of methicillin resistant and susceptible Staphylococcus aureus in Egypt. Cell Mol Biol (Noisy-le-grand) 2015; 61(4): 101-112. (PMID: 26429300)

10. Rahimi F, Bouzari M. Biochemical fingerprinting of methicillin-resistant Staphylococcus aureus isolated from sewage and hospital in Iran. Jundishapur J Microbiol 2015; 8(7): e19760. (doi: 10.5812/jjm.19760v2) (PMID: 26421131)

11. Yu F, Liu Y, Lv J, Qi X, Lu C, Ding Y, et al. Antimicrobial susceptibility, virulence determinant carriage and molecular characteristics of Staphylococcus aureus isolates associated with skin and soft tissue infections. Braz J Infect Dis 2015; 19(6): 614-622. (doi: 10.1016/j.bjid.2015.08.006) (PMID: 26408338)

12. de Oliveira CF, Morey AT, Santos JP, Gomes LV, Cardoso JD, Pinge-Filho $P$, et al. Molecular and phenotypic characteristics of methicillinresistant Staphylococcus aureus isolated from hospitalized patients. J Infect Dev Ctries 2015; 9(7): 743-751. (doi: 10.3855/jidc.5868) (PMID: 26230125)

13. Lee TM, Yang MC, Yang TF, Lee PL, Chien HI, Hsueh JC, et al. Molecular characterization of community- and healthcare-associated methicillinresistant Staphylococcus aureus isolates in Southern Taiwan. Microb Drug Resist 2015; 21(6): 610-621. (doi: 10.1089/mdr.2015.0020) (PMID: 26167865)

14. Demirel G, Findik D, Dagi HT, Arslan U. Communıty-acquıred methicillin-resistant Staphylococcus aureus and genotypes among university students in Turkey. Southeast Asian J Trop Med Public Health 2014; 45(6): 1401-1409. (PMID: 26466426)

15. Kırca Yılmaz S, Acuner IC, Strommenger B, Bek Y, Witte W. Infectivityresistotype-genotype clustering of methicillin-resistant Staphylococcus aureus strains in the Central Blacksea Region of Turkey. Mikrobiyol Bul 2014; 48(1): 14-27. (PMID: 24506712)

16. Yılmaz S, Kılıç A, Karagöz A, Bedir O, Usküdar Güçlü A, Başustaoğlu AC. Investigation of various virulence factors among the hospital and community-acquired Staphylococcus aureus isolates by real-time PCR method. Mikrobiyol Bul 2012; 46(4): 532-545. (PMID: 23188567)

17. Gülmez D, Sancak B, Ercis S, Karakaya J, Hasçelik G. Investigation of SCCmec types and Panton-Valentine leukocidin in community-acquired and nosocomial Staphylococcus aureus strains: comparing skin and soft tissue infections to the other infections. Mikrobiyol Bul 2012; 46(3): 341-351. (PMID: 22951646)

18. Baran CB, Mutlu D, Baysan BO, Günseren F, Ergani A, Oğünç D, Colak $D$. Investigation of Panton-Valentine leukocidin gene, SCCmec gene cassette types and genotypes of methicillin-resistant Staphylococcus aureus strains isolated from outpatients. Mikrobiyol Bul 2010; 44(4): 533-545. (PMID: 21063965)

19. Akoğlu H, Zarakolu $P$, Altun B, Ünal S. Epidemiological and molecular characteristics of hospital-acquired methicillin-resistant Staphylococcus aureus strains isolated in Hacettepe University Adult Hospital in 2004-2005. Mikrobiyol Bul 2010; 44(3): 343-355. (PMID: 21063984) 
Authors:

Aysegül Copur-Cicek - MD, Associate Professor, Department of Medical Microbiology, Faculty of Medicine, Recep Tayyip Erdogan University, Rize, Turkey.

Rukiye Dinc-Patlak - BSc, Biology and Medical Research Laboratory, Saxion University of Applied Sciences, Enschede, Netherlands.

Cemal Sandalli - PhD, Associate Professor, Department of Biology, Faculty of Science and Literature, Recep Tayyip Erdogan University, Rize, Turkey.

Zafer Mengeloğlu - MD, Associate Professor, Department of Medical Microbiology, Faculty of Medicine, Abant Izzet Baysal University, Bolu, Turkey.

Ugur Kostakoglu - MD, Assistant Professor, Department of Infectious Diseases and Clinical Microbiology, Faculty of Medicine, Recep Tayyip Erdogan University, Rize, Turkey.

Ilknur Esen Yildiz - MD, Assistant Professor, Department of Infectious Diseases and Clinical Microbiology, Faculty of Medicine, Recep Tayyip Erdogan University, Rize, Turkey. 